\title{
KETERAMPILAN MENULIS TEGAK BERSAMBUNG MAHASISWA CALON GURU SEKOLAH DASAR
}

\author{
Fetty Fellasufah ${ }^{1}$ \\ Ali Mustadi ${ }^{2}$ \\ ${ }^{1}$ Universitas Negeri Yogyakarta, fettyfellasufah.2017@student.uny.ac.id \\ ${ }^{2}$ Universitas Negeri Yogyakarta, ali_mustadi@uny.ac.id
}

\begin{abstract}
In this study, it will be known the implementation and results of cursive handwriting on the prospective teacher. This study uses a case study of qualitative research. The study involved 39 prospective elementary school teacher to collect data on the implementation, difficulties, and instructions used in the teaching of cursive handwriting. The research data were collected using observation and interview techniques which were verified as valid by data triangulation techniques. The data that has been collected is analyzed through qualitative descriptive techniques. The results showed that the teaching of writing was carried out by assignments continuously and intensively. The teaching of cursive handwriting helps students to get used to write cursive handwriting better.
\end{abstract}

Keywords: cursive handwriting, prospective elementary school teachers, teaching writing

\begin{abstract}
Abstrak: Pada penelitian ini akan diketahui pelaksanaan dan hasil pengajaran menulis tegak bersambung pada mahasiswa calon guru. Penelitian ini menggunakan jenis penelitian kualitatif studi kasus. Penelitian melibatkan 39 mahasiswa calon guru sekolah dasar untuk mengumpulkan data tentang pelaksanaan, kesulitan, dan instruksi yang digunakan dalam pengajaran menulis tegak bersambung. Data penelitian dikumpulkan dengan teknik obervasi dan wawancara yang dicek keabsahannya dengan teknik triangulasi data. Data yang telah terkumpul dianalisis melalui teknik deskriptif kualitatif. Hasil penelitian menunjukkan bahwa pengajaran menulis dilaksanakan dengan penugasan secara kontinu dan intensif. Pengajaran menulis tegak bersambung membantu mahasiswa untuk terbiasa menulis tegak bersambung dengan lebih baik.
\end{abstract}

Kata kunci: menulis tegak bersambung, calon guru sekolah dasar, pengajaran menulis

Keterampilan menulis berperan penting dalam proses pendidikan sejak di bangku sekolah dasar. Keterampilan menulis diajarkan secara berjenjang mulai dari menulis permulaan, menulis terbimbing, menulis kreatif, atau menulis indah (Bulut, 2017). Terdapat dua bentuk tulisan tangan yang hendaknya diajarkan kepada siswa yakni manuskrip atau huruf cetak dan kursif atau bersambung (Donoghue, 2009:296). Di Indonesia, menulis bersambung disebut dengan istilah 
tegak bersambung dengan penulisan secara tegak dengan garis penghubung yang ditulis miring berbeda dengan negara lain yang ditulis secara miring.

Di usia sekolah dasar, khususnya pada kelas rendah, menulis tegak bersambung ditujukan untuk mengembangkan keterampilan kognitif dan motorik halus. Menulis tegak bersambung membutuhkan keahlian siswa dalam merangkai huruf sebagai proses produksi simbol dalam sebuah kata (Tompkins, 1995: 480). Menulis dengan tegak bersambung membutuhkan koordinasi kemampuan kognitif, motorik dan neuromotorik (Dinehart, 2015). Selain dapat dinilai dari segi keindahan, penulisan tegak bersambung juga dapat dinilai dari segi kerapian dan kesejajaran bentuk huruf, kualitas garis, ukuran, kemiringan, dan jarak (Donoghue, 2009:305).

Selain mengembangan keterampilan kognitif dan motorik, menulis tegak bersambung juga ditujukan untuk mengembangkan keterampilan berkomunikasi secara tertulis peserta didik melalui kegiatan menulis indah. Khusus pada menulis tegak bersambung difokuskan pada keterbacaan dan kelancaran tulisan yang mampu dihasilkan peserta didik. Keterbacaan dan kelancaran berkaitan dengan kejelasan penulisan huruf dan kata untuk dipahami oleh pembaca (Tompkins, 1995; Dinehart, 2015). Kedua indikator ini dikembangkan dan akan berdampak pada hasil tulisan tangan siswa selanjutnya karena terbiasa menulis dengan rapi sejak dini.

Sebagai keterampilan, menulis tegak bersambung membutuhkan pengajaran yang konkret bagi peserta didik. Pengajaran ini menuntut keterampilan guru dalam menulis tegak bersambung sebagai pemodelan siswa untuk belajar menulis tegak bersambung (Graham, 2006). Calon guru hendaknya dipersiapkan sedemikian rupa dalam jenjang pendidikannya untuk dapat menjadi guru profesional sekaligus role model bagi siswa dalam menulis. Hal ini sejalan dengan penelitian Karadağ (2014) tentang pentingnya keterampilan menulis tegak bersambung bagi calon guru dalam pengajaran menulis di sekolah dasar. Dari pemaparan tersebut, pada artikel ini akan dideskripsikan proses pengajaran menulis tegak bersambung mahasiswa calon guru sekolah dasar.

\section{METODE}

Penelitian ini menggunakan desain penelitian studi kasus yang termasuk dalam jenis penelitian kualitatif. Data penelitian dihimpun dengan teknik observasi, wawancara, dan studi dokumentasi. Instrumen utama yang digunakan adalah peneliti sendiri (human instrument) dengan bantuan pedoman observasi dan wawancara. Penelitian ini melibatkan 39 mahasiswa PGSD pada Semester II sebagai responden dengan teknik pengkodean seperti pada Tabel 1.

Pada penelitin ini akan diperoleh data tentang proses pengajaran yang melibatkan keterampilan menulis, kesulitan dalam keterampilan menulis, dan instruksi pengajaran untuk mengatasi kesulitan menulis tegak bersambung. Dari data tersebut, dilakukan pengecekan keabsahan data melalui teknik triangulasi data yang dianalisis dengan teknik deskriptif kualitatif 
secara berkelanjutan. Hasil penelitian ini didasarkan pada kriteria validitas yaitu, derajat kepercayaan, keteralihan, kebergantungan, dan kepastian data hasil penelitian.

Tabel 1. Kode Partisipan

\begin{tabular}{cc}
\hline Identitas Responden & Kode \\
\hline MS & M1 \\
DRW & M2 \\
ENH & M3 \\
NK & M4 \\
MNA & M5 \\
dst & $\ldots$ \\
\hline
\end{tabular}

\section{HASIL DAN PEMBAHASAN}

Dari hasil penelitin ini diketahui bahwa keterampilan menulis selalu diajarkan dalam matakuliah Bahasa Indonesia. Lebih spesifik pada keterampilan menulis tegak bersambung, berdasarkan pernyataan diketahui 54\% mahasiswa calon guru sekolah dasar masih merasa kesulitan dalam menulis tegak bersambung dan $46 \%$ mahasiswa calon guru sekolah dasar tidak merasa kesulitan. Pada prosesnya, responden menyatakan bahwa pengajaran bahasa Indonesia selama perkuliahan cukup membantu dalam peningkatan dan pengembangan keterampilan menulis. Dari hasil wawancara tentang keterlibatan mahasiswa selama mengikuti mata kuliah bahasa Indonesia, diketahui bahwa rata-rata mahasiswa mampu mengikuti proses pengajaran yang diberikan oleh dosen. Berikut beberapa sampel transkrip hasil wawancara dari responden yang terekam dalam penelitian ini (Tabel 2).

Tabel 2. Transkrip Wawancara dari Responden

\begin{tabular}{|c|c|c|}
\hline No & Kode & Transkrip \\
\hline 1 & M6 & $\begin{array}{l}\text { "selama saya mengikuti mata kuliah ini, dosen selalu meminta mahasiswa untuk } \\
\text { menulis atau merangkum materi yang disampaikan kelompok penyaji..." }\end{array}$ \\
\hline 2 & M15 & $\begin{array}{l}\text { "saya biasanya menulis memakai huruf tegak bersambung hanya di mata kuliah } \\
\text { Bahasa Indonesia..." }\end{array}$ \\
\hline 3 & M7 & "setiap minggunya selalu ada tugas menulis menggunakan huruf tegak berambung..." \\
\hline 4 & M11 & $\begin{array}{l}\text { "dosen sering meminta mahasiswa untuk maju kedepan kelas untuk menjawab soal, } \\
\text { dan ditulis di papan tulis, seperti membuat kalimat dan lain-lain..." }\end{array}$ \\
\hline 5 & M20 & $\begin{array}{l}\text { "kalau saat menjelaskan materi bisa saja ditengah-tengah dosen meminta mahasiswa } \\
\text { membuat kalimat, jadi kita harus siap-siap menulis dan benar-benar memperhatikan..." }\end{array}$ \\
\hline 6 & M21 & $\begin{array}{l}\text { "di akhir selalu ada penugasan, kalau selesai dikumpulkan, kalau tidak dilanjutkan } \\
\text { dirumah..." }\end{array}$ \\
\hline 7 & M23 & "penugasannya ditulis di buku tulis halus, semua harus punya..." \\
\hline 8 & M30 & $\begin{array}{l}\text { "iya, selalu ada tugas evaluasi, jika sudah selesai dikumpulkan dan langsung diberikan } \\
\text { nilai oleh dosen..." }\end{array}$ \\
\hline 9 & M33 & $\begin{array}{l}\text { "kita diberikan tugas dan langsung diberikan penilaian, tugas ditulis memakai huruf } \\
\text { tegak bersambung di buku tulis halus kami, jadi karena sudah terlalu banyak satu buku } \\
\text { saja tidak cukup..." }\end{array}$ \\
\hline 10 & M9 & $\begin{array}{l}\text { "setiap kali pertemuan, dosen memberikan tugas berupa soal evaluasi yang kemudian } \\
\text { ditulis menggunakan huruf tegak bersambung..." }\end{array}$ \\
\hline
\end{tabular}

Berdasarkan paparan data pada Tabel 1 dapat diketahui bahwa pengajaran menulis tegak bersambung dilaksanakan dalam pengajaran Bahasa Indonesia. Pengajaran menulis tegak 
bersambung dilaksanakan secara kontinu dan intensif dengan penugasan serta penilaian dari dosen. Pada prosesnya, dosen seringkali memberikan intruksi untuk menulis tegak bersambung pada mahasiswa di awal, tengah, dan akhir pengajaran. Dosen mengintruksikan mahasiswa untuk wajib memiliki buku halus. Berikut gambar proses dan hasil penugasan menulis tegak bersambung pada mahasiswa yang ditulis dalam buku tulis halus (Gambar 1).

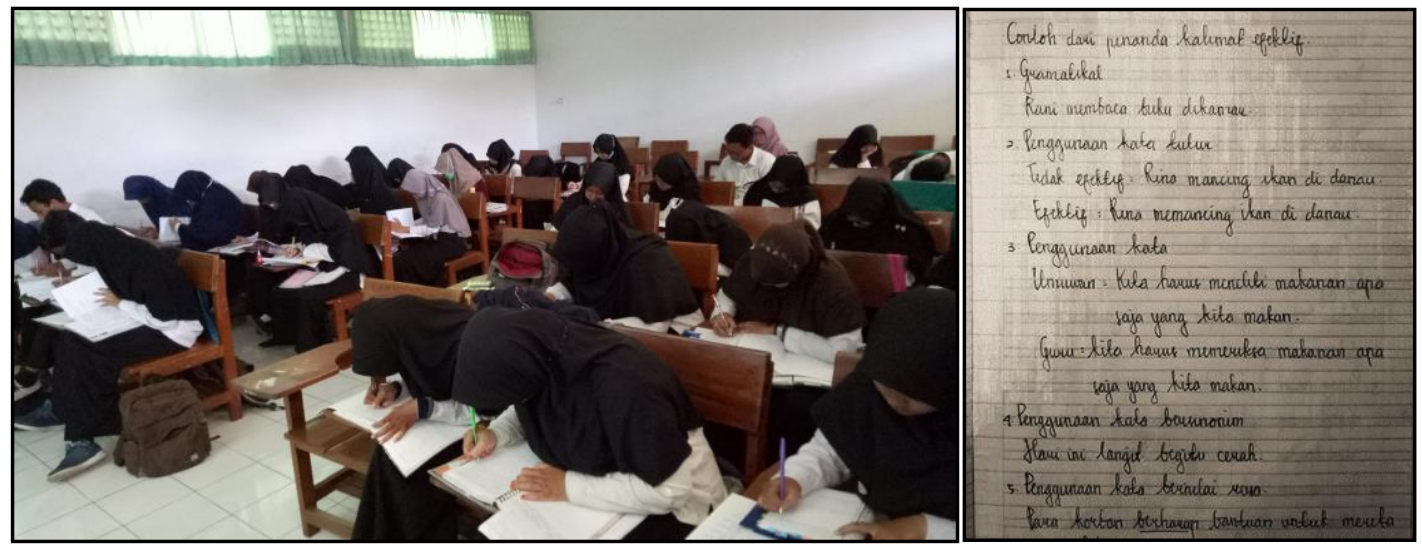

Gambar 1. Hasil Penugasan Menulis Tegak Bersambung Mahasiswa

Dari hasil observasi yang dilakukan selama proses pengajaran berlangsung, ketika diberikan tugas baik ditulis di buku maupun di papan tulis mahasiswa menuliskannya menggunakan huruf tegak bersambung. Semua mahasiswa membawa buku tulis halus sebagai buku tugasnya, bahkan diketahui satu mahasiswa membawa tiga buku tulis halus yang dijilid menjadi satu, khusus untuk mata kuliah Bahasa Indonesia mulai dari semester satu.

Sesuai hasil penelitian, keterampilan menulis tegak bersambung diajarkan secara berkelanjutan pada mahasiswa calon guru. Pengajaran ini sesuai dengan tiga fungsi utama pendidikan untuk pengembangan kecerdasan, penanaman nilai-nilai, dan kemampuan atau keterampilan dasar (Mustadi, 2009). Keterampilan menulis tegak bersambung ini mendukuki keterampilan dasar yang terus dikembangkan dalam proses pengajaran yang disisipkan dalam mata kuliah bahasa Indonesia. Pengajaran dan pengembangan keterampilan menulis tegak bersambung secara bekelanjutan bertujuan untuk membiasakan mahasiswa calon guru dalam menulis (Sulak, 2018).

Keterampilan menulis tegak bersambung diajarkan dalam bentuk penugasan individu yang dituliskan dalam buku tulis halus sebagai media. Sebagaimana diketahui bahwa buku tulis halus memiliki garis-garis yang dijadikan patokan dalam menulis yang bertujuan agar bentuk tulisan menjadi indah, rapi, dan dapat terbaca dengan mudah (Simonnet. dkk, 2018). Hal ini didukung dengan hasil penelitian Read (2007) yang menunjukkan adanya dampak signifikan dari pengajaran menulis tegak bersambung terhadap hasil penulisan ejaan yang lebih baik. 
Dari hasil pengumpulan data, diketahui pula bahwa seluruh mahasiswa pada kelas tersebut mengikuti proses pengajaran yang diberikan dosen dengan baik. Mahasiswa brpartisipasi aktif selama kegiatan pengajaran maupun ketika diberikan penugasan. Alur pengumpulan tugas dilaksanakan dengan rutin pada setiap pertemuan yang disertai dengan feedback dari dosen (Fauziah, 2018). Feedback dalam bentuk catatan revisi dan remidial membantu dalam penguatan hasil tulisan mahasiswa sehingga mahasiswa memahami dengan benar bagian-bagian yang perlu diperbaiki dan ditingkatkan saat menulis tegak bersambung (Dinehart, 2015).

Dari metode pengajaran yang digunakan, mahasiswa menyatakan sangat terbantu terkait keterampilannya dalam menulis tegak bersambung. Tulisan tegak bersambung membantu mengembangkan kemampuan membaca, komunikasi, dan keterampilan motorik halus siswa (Widianingrum \& Hartono, 2016). Berlatih menulis tegak bersambung meningkatkan bentuk lintasan huruf dan tulisan tangan karena motoriknya menjadi terlatih (Vinter \& Chartrel, 2010). Di Indonesia menulis tegak bersambung diajarkan kepada siswa sekolah dasar mulai dari kelas satu, berbeda dengan negara asing yang mengajarkan tulisan bersambung pada siswa di kelas dua dan tiga (Erdogan \& Erdogan, 2012).

Melalui pembiasaan menulis tegak bersambung, merupakan langkah awal untuk mendukung keterampilan menulis mahasiswa yang nantinya dapat diterapkan ketika mengajar. Pelatihan menulis pada mahasiswa calon guru akan berdampak kemampuan guru dalam melakukan pengajaran tulisan bersambung (Karadağ, 2014). Pada usia awal menulis, hendaknya guru menyampaikannya dan memberikan materi tentang menulis tegak bersambung dengan contoh atau praktik langsung (Geller. dkk, 2018) secara berkelanjutan agar mahasiswa semakin lancar dalam menulisnya (Marquardt. dkk, 2016).

\section{SIMPULAN DAN SARAN}

\section{Simpulan}

Dari hasil penelitian dapat ditarik kesimpulan bahwa proses pengajaran menulis tegak bersambung dilaksanakan dengan penugasan secara kontinu dan intensif. Pengajaran menulis tegak bersambung diajarkan dalam matakuliah yang relevan yang diintruksikan pada setiap kegiatan yang memungkinkan mahasiswa untuk menulis. Pengajaran ini menjadi upaya dalam meningkatkan keterampilan menulis tegak bersambung mahasiswa calon guru sekolah dasar dengan instruksi dan feedback rutin dari dosen.

\section{Saran}

Dari hasil penelitian ini direkomendasikan untuk melaksanakan pengajaran menulis tegak bersambung bagi calon guru sekolah dasar sebagai upaya mencetak guru yang profesional. Pengajaran menulis tegak bersambung disarankan untuk dilaksanakan secara berkelanjutan dan 
intensif yang mengkondisikan agar mahasiswa lebih banyak melakukan praktik menulis secara langsung.

\section{DAFTAR RUJUKAN}

Bulut, P. (2017) Effect of Primary School Students' Writing Attitudes and Writing Self Eficacy Beliefs on Their Summary Writing Achievement. International Electroncs Journal of Elementary School, 10(2), 281-285, https://doi.org/10.26822/Iejee.2017236123.

Dinehart, L. H. (2015). Handwriting In Early Childhood Education: Current Research And Future Implications. Journal Of Early Childhood Literacy, 15(1), 97-118, https://doi.org/10.1177/1468798414522825.

Donoghue, M.R. (2009). Language Art "Integrating Skills for Classroom Teaching. Los Angeles: SAGE Erdogan, T., \& Erdogan, O. (2012). An Analysis Of The Legibility Of Cursive Handwriting Of Prospective Primary School Teachers. Procedia - Social And Behavioral Sciences, 46, 5214-5218, https://doi.org/10.1016/j.sbspro.2012.06.412.

Fauziah, A. (2018). Peningkatkan Keterampilan Menulis Tegak Bersambung Menggunakan Strategi Kontekstual Kelas II SD. Basic Education, 7(39), 3-920.

Geller, J., Still, M. L., Dark, V. J., \& Carpenter, S. K. (2018). Would Disfluency By Any Other Name Still Be Disfluent? Examining The Disfluency Effect With Cursive Handwriting. Memory and Cognition, 46(7), 1109-1126, https://doi.org/10.3758/s13421-018-0824-6.

Graham, S. (2006). Strategy Instruction And The Teaching Of Writing. In C. Macarthur, S. Graham \& J. Fitzgerald (Eds.) Handbook Of Writing Research 187-207. New York: The Guilford Press

Karadağ, R. (2014). The Attitudes Of Primary School Pre-Service Teachers Towards Cursive Handwriting. Mevlana International Journal Of Education, 4(1), 82-95.

Marquardt, C., Diaz Meyer, M., Schneider, M., \& Hilgemann, R. (2016). Learning Handwriting At School A Teachers' Survey On Actual Problems And Future Options. Trends In Neuroscience And Education, 5(3), 82-89, https://doi.org/10.1016/j.tine.2016.07.001.

Mustadi, A. (2009). Pengembangan Writing Instruction melalui Beyond Centers and Circles Time Matkul Bahasa Inggris di PSD. Jurnal Penelitian Ilmu Pendidikan, 2(2), 1-21.

Read, J. C. (2007). A Study Of The Usability Of Handwriting Recognition For Text Entry By Children. Interacting With Computers, 19(1), 57-69, https://doi.org/10.1016/j.intcom.2006.08.009.

Simonnet, D., Girard, N., Anquetil, E., Renault, M., \& Thomas, S. (2018). Evaluation Of Children Cursive Handwritten Words For E-Education. Pattern Recognition Letters, 121, 133-199, https://doi.org/10.1016/J.Patrec.2018.07.021.

Sulak, S. E. (2018). Investigation Of Writing Habits Of Primary School Teachers. International Electronic Journal Of Elementary Education, 10(4), 497-504. DOI: https://doi.org/10.26822/iejee.2018438140

Tompkins, G. E. (1995). Language Arts Contens and Teaching Strategies. New Jersey: Prentice Hall.

Vinter, A., \& Chartrel, E. (2010). Effects Of Different Types Of Learning On Handwriting Movements In Young Children. Learning And Instruction, 20(6), 476-486, https://doi.org/10.1016/j.learninstruc.2009.07.001.

Widianingrum, U. W., \& Hartono, Y. (2016). Peningkatan Keterampilan Menulis Tegak Bersambung melalui Media Kartu Magic. Didaktika Dwija Indria, 4(7). 